\title{
Clinical Significance of Maxillary Artery and its Branches: A Cadaver Study and Review of the Literature
}

\author{
Significado Clínico de la Arteria Maxilar y sus Ramas: \\ Un Estudio en Cadáver y la Revisión de la Literatura
}

"Ismihan Ilknur Uysal; "*Mustafa Buyukmumcu; *Nadire Unver Dogan; "*Muzaffer Seker \& **Taner Ziylan

UYSAL, I. I,; BUYUKMUMCU, M.; DOGAN, N. U.; SEKER, M. \& ZIYLAN, T. Clinical significance of maxillary artery and its branches: A cadaver study and review of the literature. Int. J. Morphol., 29(4):1274-1281, 2011.

SUMMARY: The aim of this study was to investigate the anatomy of the maxillary artery (MA) and its branches. Fourteen sides of Turkish adult cadavers were dissected. The specimens were classified according to the relation between MA and the lateral pterygoid. After the removal of the lateral pterygoid, parts and branches of MA were exposed. We classified the branching patterns of MA in the pterygopalatine fossa. The calibers and lengths of the arteries, and the distance between the zygomatic arch and MA, and between the infratemporal crest and MA were measured. The MA was found superficial to the lateral pterygoid in 57.2\%. The inferior alveolar artery (IA) was arisen from MA before the middle meningeal artery (MM) in 35.7\%, after MM in 35.7\%. The IA and MM were arisen from the same area of MA in $14.3 \%$. In other two cases IA was arisen from the beginning of MA (14.3\%). According to the contours of third portion of MA, we classified "Y" type (50\%), "intermediate-T" type (14.3\%), and "M" type (35.7\%). This reinvestigation of the clinical anatomy of MA may provide useful information to the head and neck surgeons, dentists, neurosurgeons and radiologists related with this region.

KEY WORDS: Maxillar artery; Inferior alveolar artery; Middle meningeal artery; Human cadaver.

\section{INTRODUCTION}

Having an important role in blood supply of deep facial structures, maxillary artery (internal maxillary artery) is the thickest end branch of the external carotid artery. Maxillary artery branches from the external carotid artery in deep regions of neck of mandible and in the parotid gland with almost a perpendicular angle. It has a corrugated course, it generally progresses towards superior and ends in pterygopalatine fossa. It will be described in three parts including mandibular part (neighbor to the neck of mandible and lies to lower border of lateral pterygoid (externa)), pterygoid part (lies between lower and upper borders of lateral pterygoid) and pterygopalatine part (found in the pterygopalatine fossa after it passes lateral pterygoid) (Abelson et al., 1991; Maceri, 1993; Standring et al., 2005).

Although course and parts of the maxillary artery are defined in classical anatomy books, significant clinical information related with the main artery and its branches are included in several investigation reports (Navarro et al., 1982; Morton \& Khan, 1991; Vrionis et al., 1996; Sashi et al., 1996;
Choi \& Park, 2003; Schwartzbauer et al., 2003; Isolan et al., 2007; Hussain et al., 2008; Abuzayed et al., 2009; Chiu, 2009; Kwak et al., 2010). As the most important contribution to the blood supply of the nose is made by maxillary artery from the external carotid system, it is reported that ligation of the maxillary artery and its branches via different procedures is the most efficient method for controlling the epistaxis (Stepnick et al., 1990; Abelson, 1991; Maceri, 1993; Abuzayed et al., 2009; Kwak et al., 2010). In some persistent epistaxis cases, the angiography guided arterial embolization is mentioned as an efficient and alternative method of arterial ligation (Maceri). Due to close proximity with cranial base, there are studies investigating the availability of maxillary artery directly as arterial donor in the repair of internal carotid artery dissections and aneurysms (Vrionis et al., 1996; Buyukmumcu et al., 2003). It is emphasized that maxillary artery should be cared both due to intra-arterial injection risk during dental anesthesia (Pretterklieber et al., 1991) and to bleeding control during removal of different tumors found in the infratemporal fossa (Isolan et al.).

\footnotetext{
* Selcuk University, Selcuklu Medical Faculty, Department of Anatomy, Konya, Turkey.

** Selcuk University, Meram Medical Faculty, Department of Anatomy, Konya, Turkey.
} 
In this study, it is aimed to examine morphological and morphometric features of maxillary artery and its important branches (except muscular branches), determine relations with neighbor structures and to emphasize clinical importance throughout whole course using the adult cadaver.

\section{MATERIAL AND METHOD}

Fourteen hemicraniums of different age and gender (7 adult cadaver heads) embalmed with formalin were dissected. Neck of mandible was removed and maxillary artery was exposed. Samples were classified according to relationship of maxillary artery with lateral pterygoid and zygomatic arch.

Superficial course: Cases lying lateral to the lateral pterygoid and with distance between zygomatic arch and maxillary artery $\leq 20 \mathrm{~mm}$,

Deep type course: Cases lying medial to the lateral pterygoid and with distance between zygomatic arch and maxillary artery $>20 \mathrm{~mm}$ (Fig. 1a-b).

After relation of maxillary artery with lateral pterygoid was determined, inferior part of the muscle was removed. Course, branch distribution, variations and relations with neighbor structures (infratemporal crest, lingual nerve, inferior alveolar nerve) of maxillary artery were examined. Last part of the maxillary artery was determined as type "Y", type "intermediate-T" and type "M" according to the classification based on how sphenopalatine artery and descending palatine artery from the maxillary artery (Fig." 2a-c) (Morton \& Khan).

All dissections were performed by the same investigator under microscope. Following the morphological examination, measurements were obtained using digital caliper $(150 \mathrm{x} 0.01 \mathrm{~mm})$. Mean of sequential 3 measurements was recorded.

Diameter measurements: Diameters of the maxillary artery (M) (just after it branches from external carotid artery (Ma), after it gives middle meningeal artery (Mb), after it gives inferior alveolar artery $(\mathrm{Mc})$, before it gives infraorbital artery (Md)) and its branches at the branching point (middle meningeal artery (MM), inferior alveolar artery (IA), sphenopalatine artery (SP), infra-orbital artery (IO) and descending palatine artery (DP)) were measured throughout the course of maxillary artery.

Thickness measurements; Thickness of inferior alveolar nerve (IAN) and lingual nerve (LN) were measured.

Length measurements; Lengths between origin of the maxillary artery and middle meningeal artery (M-MM), between origin of the maxillary artery and inferior alveolar
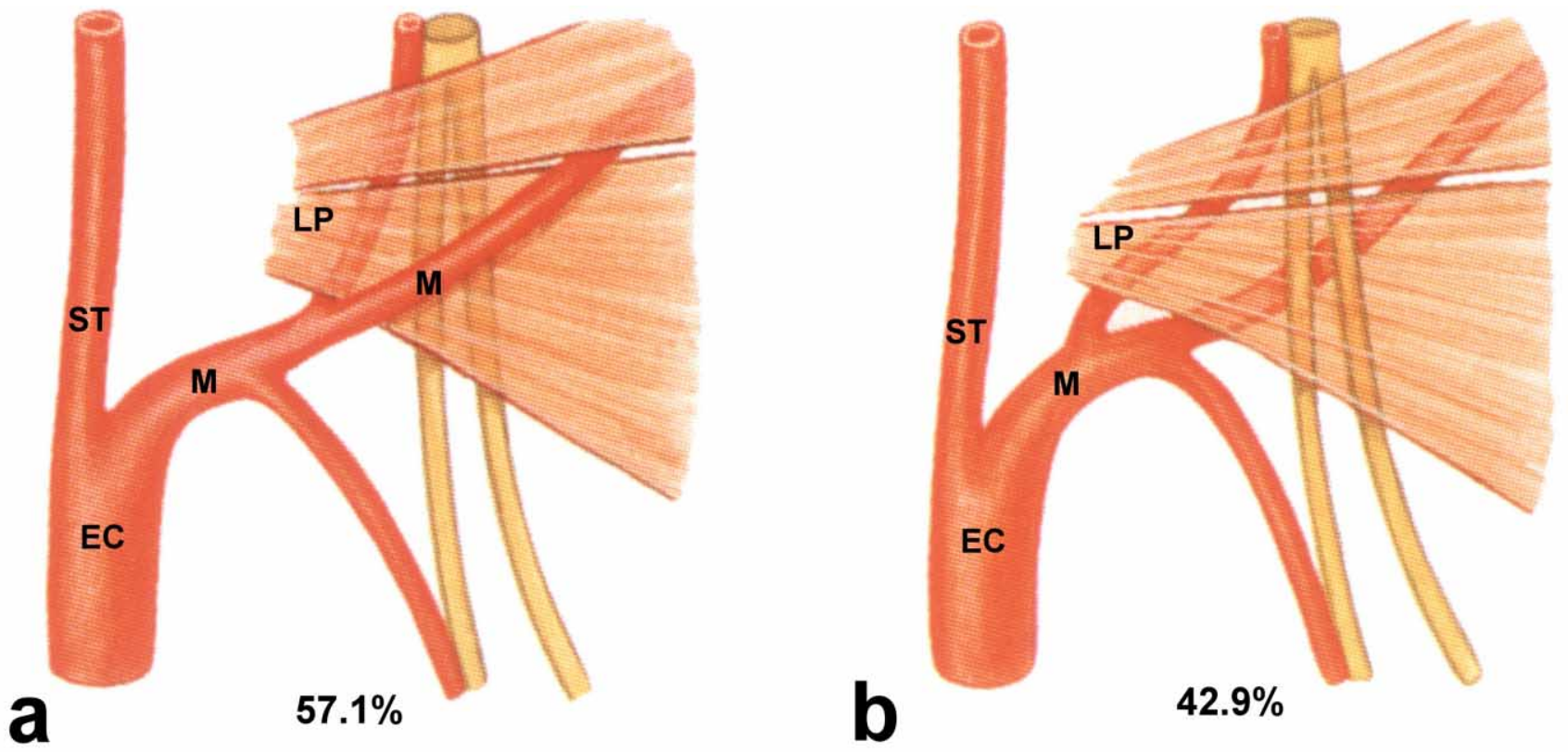

Fig.1. A-B. Classification of maxillary artery (M) as superficial (a) and deep (b) according to lateral pterygoid (LP) (referenced from Putz \& Pabst, 2001). ST, superficial temporal artery; EC, external carotid artery. 

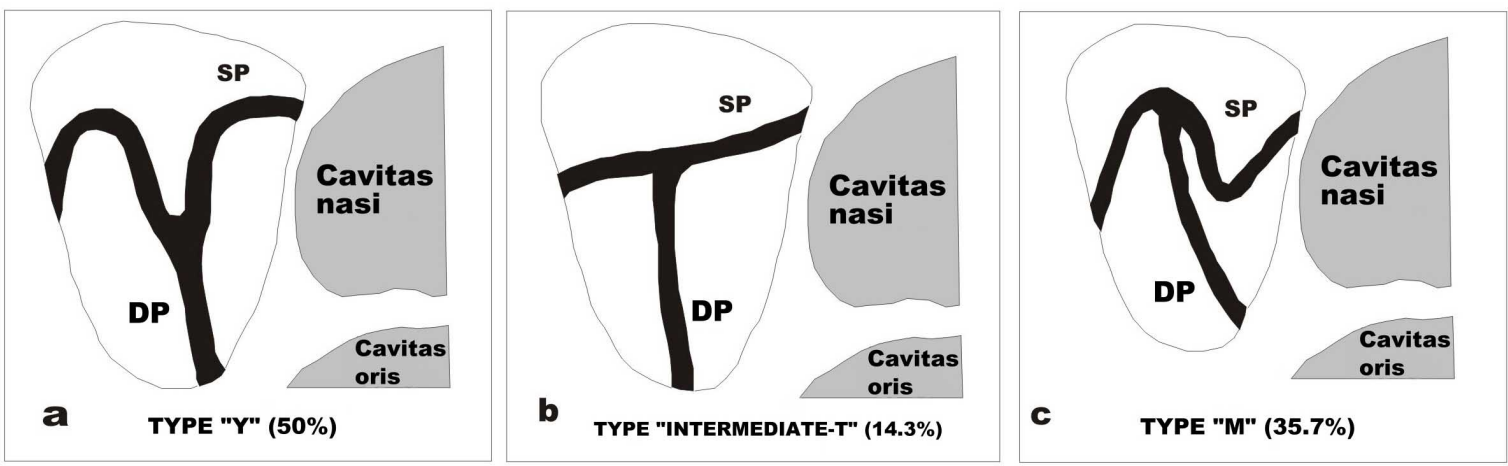

Fig. 2. A-C. Classification of maxillary artery according to the part of pterygopalatine (referenced from Morton \& Khan, 1991). SP, sphenopalatine artery; DP, descending palatine artery

artery (M-IA), between middle meningeal artery and inferior alveolar artery (MM-IA) and between middle meningeal artery and infra-orbital artery (MM-IO) were measured.

Distance measurements; Distances between zygomatic arch and maxillary artery (ZA-M), between infratemporal crest and maxillary artery (pterygopalatine part) (IT-M) and between inferior alveolar nerve and middle meningeal artery (IAN-MM) were measured.

Definitive analysis of the data obtained was performed using SPSS software package.

\section{RESULTS}

Considering cases of maxillary artery, it was observed that $57.1 \%(8 / 14)$ had superficial and $42.9 \%(6 / 14)$ had deep course (Figs. 3a-b). It was also determined that maxillary artery with superficial course passed between two heads of lateral pterygoid and arteries with deep course passed to pterygopalatine fossa from the posterior aspect of the muscle. In all cases, maxillary artery externally crossed lingual and inferior alveolar nerves.

Findings on inferior alveolar artery;

- Branching from the origin of the maxillary artery; 2 cases $(14.3 \%)$.

- Branching before the middle meningeal artery; 5 cases (35.7 \%) (Fig. 3b)

- Branching at the same localization with middle meningeal artery; 2 cases (14.3\%) (Fig.4)

- Branching after middle meningeal artery; 5 cases (35.7\%) (Fig. 5)

While middle meningeal artery was present in all cases, accessory middle meningeal artery was observed in 8 cases $(57.1 \%)$. In three of maxillary artery cases with superficial course (3/8), it was found that accessory middle meningeal artery and middle meningeal artery branched from common trunk (Fig. 3a). It was determined that one accessory middle meningeal artery passed through the fibers of inferior alveolar nerve (Fig. 6).

Table Ia. Diameters of maxillary artery (Ma, after it is given from external carotid artery).

\begin{tabular}{lcccc}
\hline & $\mathrm{Ma}$ & $\mathrm{Mb}$ & $\mathrm{Mc}$ & $\mathrm{Md}$ \\
\hline Superficial & $4.08 \pm 0.51$ & $3.18 \pm 0.49$ & $3.09 \pm 0.36$ & $2.58 \pm 0.33$ \\
Deep & $3.63 \pm 0.83$ & $2.68 \pm 0.47$ & $3.12 \pm 0.77$ & $2.72 \pm 0.47$ \\
\hline
\end{tabular}

$\mathrm{Mb}$, after it gives middle meningeal artery; Mc, after it gives inferior alveolar artery; Md, before it gives infra-orbital artery) (mean \pm standard deviation, $\mathrm{mm}$ )

Table Ib. Diameters of branches of maxillary artery (MM, middle meningeal artery).

\begin{tabular}{lccccccc}
\hline & MM & IA & DP & IO & SP & LN & IAN \\
\hline Superficial & $2.39 \pm 0.25$ & $1.39 \pm 0.14$ & $1.48 \pm 0.29$ & $1.83 \pm 0.40$ & $2.23 \pm 0.43$ & $2.47 \pm 1.03$ & $2.28 \pm 0.70$ \\
Deep & $1.93 \pm 0.37$ & $2.11 \pm 0.16$ & $1.83 \pm 0.38$ & $1.98 \pm 0.36$ & $2.43 \pm 0.36$ & $3.47 \pm 0.88$ & $2.50 \pm 0.53$ \\
\hline
\end{tabular}

IA, inferior alveolar artery; IO, infra-orbital artery; DP, descending palatine artery; SP, sphenopalatine artery) and thicknesses of neighboring nerves (LN, lingual nerve; IAN, inferior alveolar nerve) (mean \pm standard deviation, $\mathrm{mm}$ ). 

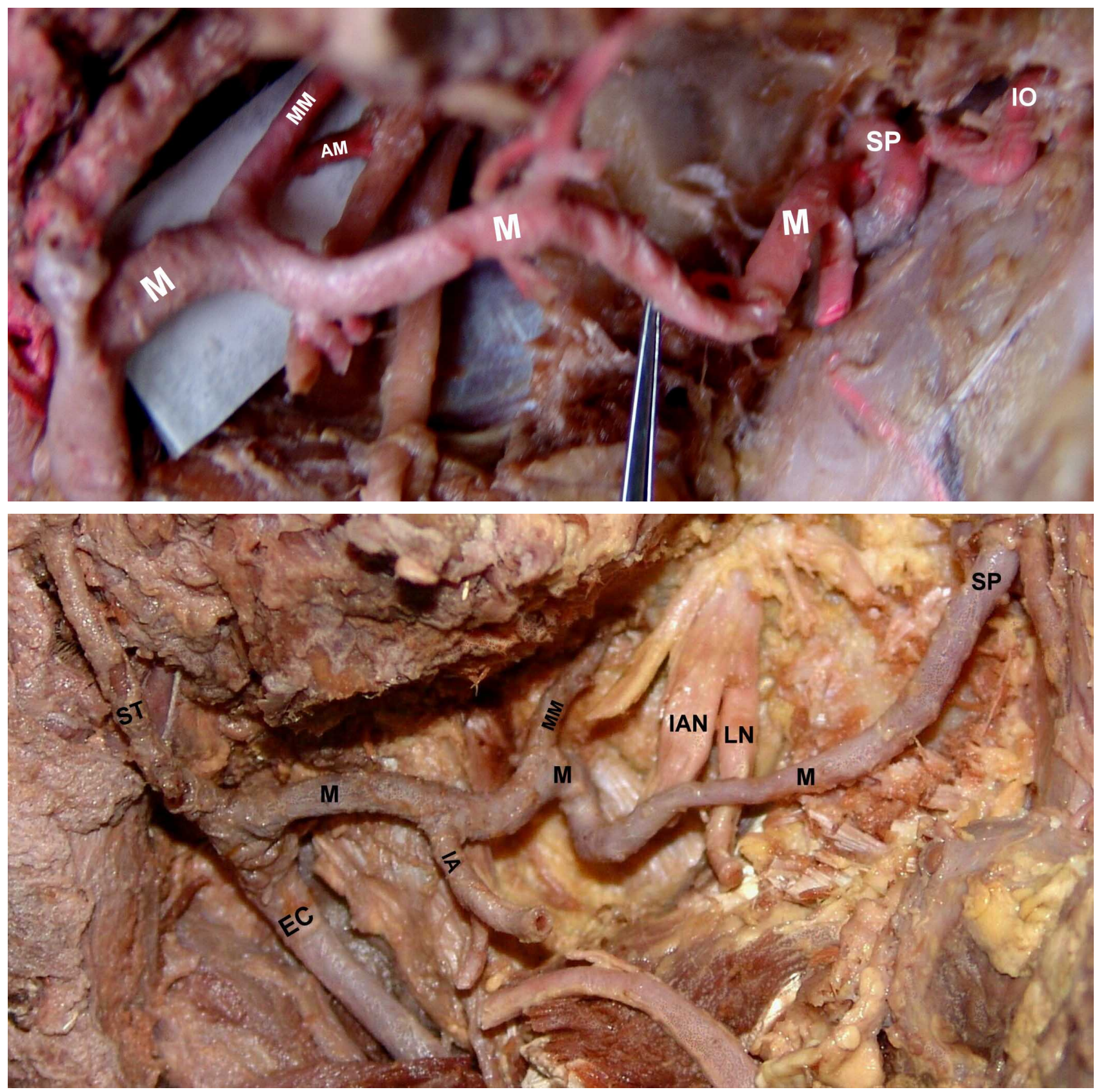

Fig. 3. A-B. A. Superficial maxillary artery (M); Middle meningeal artery (MM) and accessory meningeal artery (AM) are given from common trunk. IO, Infra-orbital artery. B. Deep maxillary artery (M); Inferior alveolar artery (IA) is given before middle meningeal artery (MM). ST, superficial temporal artery; EC, external carotid artery; IAN, inferior alveolar nerve; LN, lingual nerve; SP, sphenopalatine artery.

Based on the type of branching indicated by last part of the maxillary artery, type "Y" was found in $50 \%(7 / 14)$, type "Intermediate-T" in $14.3 \%$ (2/14) and type "M" in $35.7 \%$ (5/14) (Fig. 2a-c).

Superficial/deep course of the maxillary artery and branching pattern of the last part did not vary between right and left sides (they were symmetrical).

Diameters of maxillary artery and its branches and thickness of lingual and inferior alveolar nerves are shown in Table Ia, b and lengths and distances to neighbor structures are indicated in Table II. 


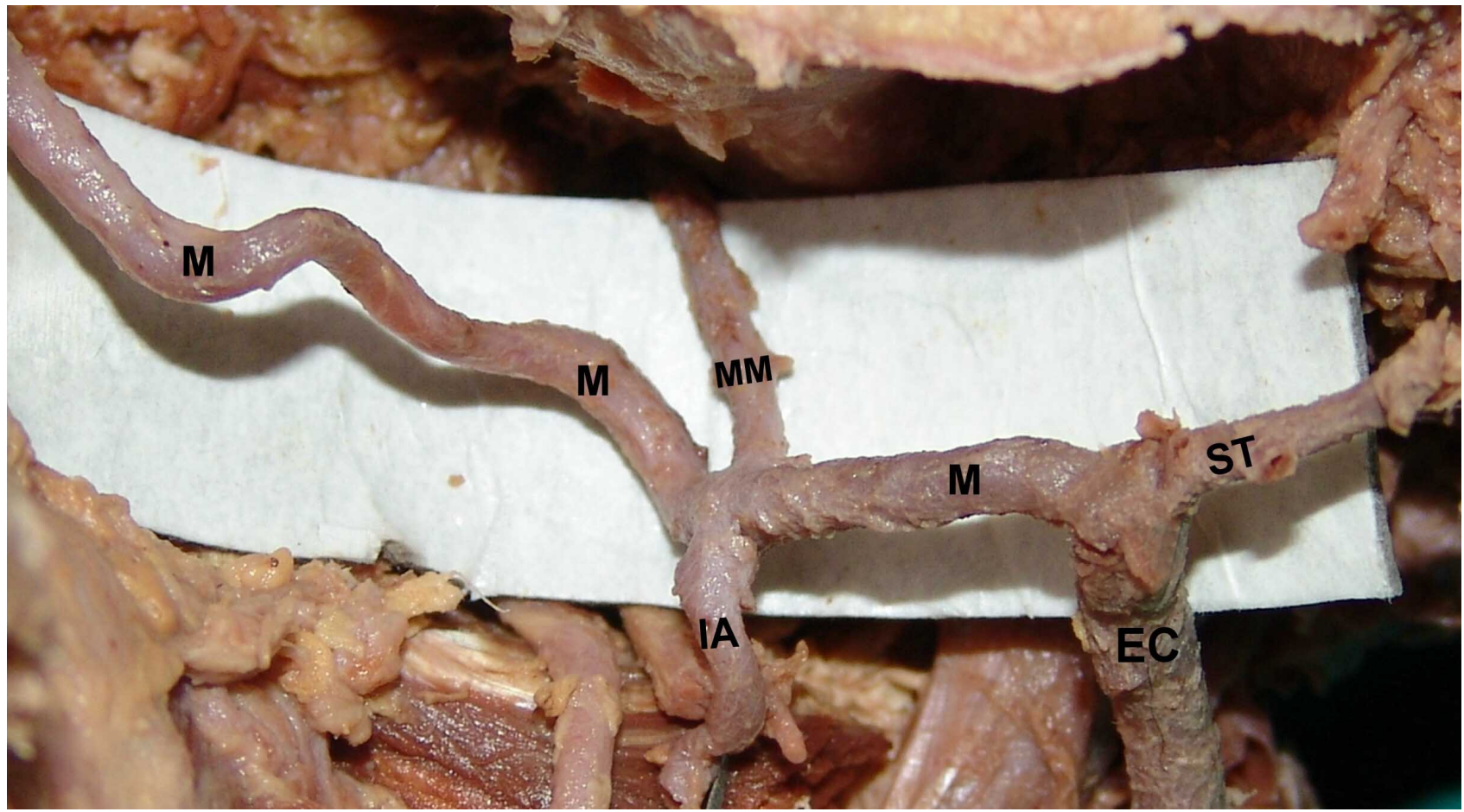

Fig. 4. Inferior alveolar artery (IA) and middle meningeal artery (MM) are given at same level. ST, superficial temporal artery; EC, external carotid artery; M, maxillary artery.

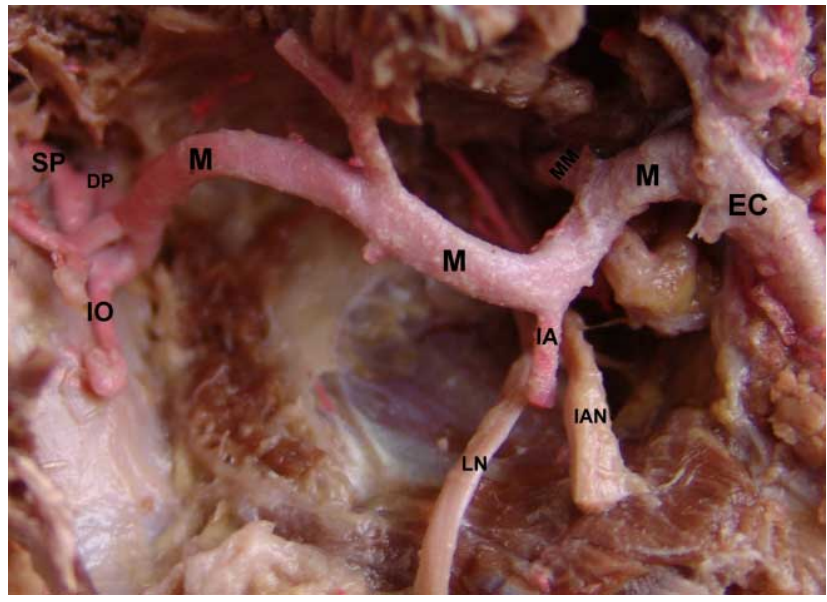

Fig. 5. Inferior alveolar artery (IA) is given after middle meningeal artery (MM). EC, external carotid artery; M, maxillary artery; SP, sphenopalatine artery; DP, descending palatine artery; IO, infraorbital artery; IAN, inferior alveolar nerve; LN, lingual nerve.

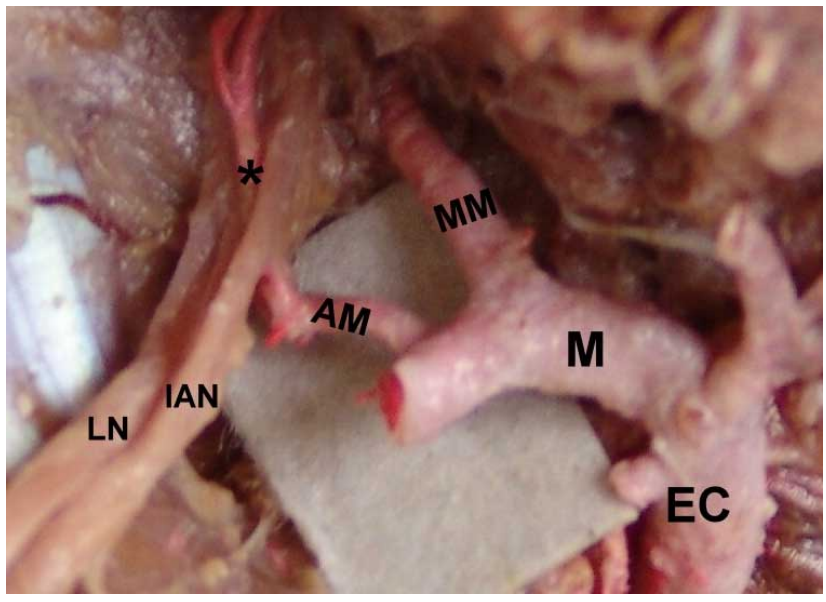

Fig. 6. Accessory meningeal artery (AM) lies among fibers of inferior alveolar nerve (IAN) (*). EC, external carotid artery; M, maxillary artery; MM, middle meningeal artery; LN, lingual nerve.

Table II. Distance and length measurements of maxillary artery with neighboring structures (mean \pm standard deviation, mm). ZA-M, distance from zygomatic arch to maxillary artery.

\begin{tabular}{lcccccccc}
\hline & ZA-M & ITC-M & IAN-MM & M-MM & MM-IO & TL & M-IA & MM-IA \\
\hline Superficial & $16.8 \pm 1.68$ & $6.64 \pm 6.33$ & $3.23 \pm 2.03$ & $10.81 \pm 3.41$ & $46.47 \pm 8.94$ & $57.28 \pm 7.12$ & $10: 81 \pm 6$ & $6.11 \pm 6.33$ \\
Deep & $30.7 \pm 3.26$ & $7.22 \pm 5.18$ & $2.87 \pm 0.85$ & $16.31 \pm 5.00$ & $37.84 \pm 5.47$ & $54.15 \pm 8.39$ & $6 \pm 4.94$ & $9.38 \pm 6.65$ \\
\hline
\end{tabular}

ITC-M, distance between infratemporal crest and maxillary artery; IAN-MM, distance between inferior alveolar nerve and middle meningeal artery. M$\mathrm{MM}$, length from origin of the maxillary artery to middle meningeal artery; MM-IO, length between middle meningeal artery and infra-orbital artery; TL (M-MM+MM-IO); total length of the maxillary artery; M-IA, length between origin of the maxillary artery and inferior alveolar artery; MM-IA, length between middle meningeal artery and inferior alveolar artery. 


\section{DISCUSSION}

There are many studies conducted on maxillary artery, which is very important with regards to localization, neighboring structures and supplying area. In general, investigations were made on parts of the maxillary artery (Navarro et al.; Morton \& Khan; Vrionis et al., 1996; Sashi et al., 1996; Choi \& Park), but some studies examined neighboring relations (Pretterklieber et al.; Sashi et al.; Hussain et al.). This study, is aimed to determine anatomic structure, neighboring relations and distances to pre-defined reference points of maxillary artery and its branches and to emphasize clinical significance from different perspectives.

In studies conducted on different races, position of maxillary artery (according to the relation with inferior part of the lateral pterygoid) was defined as superficial (lateral) or deep (medial). In a study of 180 dissections conducted by Bergman et al. (2006), it was reported that maxillary artery had superficial course in $30.5 \%$ of cases and deep course in $69.5 \%$, and in another study, the author reported $54 \%$ superficial and $46 \%$ deep course, but no racial difference was determined. In the study conducted by Pretterklieber et al., they found $55.4 \%$ superficial course in individuals born in West side of Austria, and Hussain et al., determined that course of maxillary artery is superficial in $68.2 \%$ of white race in Canada. Sashi et al. found $93 \%$ superficial type maxillary artery in 100 Japanese angiographies and the author emphasized that this rate is extremely higher than that of western population. In our study, it was found that maxillary artery had superficial course by $57.1 \%$ and deep course by $42.9 \%$ according to the relation of the artery with inferior part of lateral pterygoid. Our findings are compliant with rates of superficial maxillary artery (54-70\%) reported in white race that neighboring relation of all our cases with lateral pterygoid was symmetrical.

Infratemporal fossa defined as complicated section of the skull base, which is influenced by benign and malign tumors (Isolan et al.). Tumors of this regions cause deafness, pain in the auditory canal, anesthesia in the distribution area of mandible nerve and swelling of zygomatic arch as well as trismus (when pterygoid muscles are involved) (Lang, 1995). There are studies for determining safe surgical methods to remove tumor (for protecting maxillary artery and neighboring structures) (Isolan et al.). Good knowledge on neighboring relations is not only important for ensuring protection during the surgery, but it is also important for explaining some findings, before the treatment is applied. It should be kept in mind that trismus arising from the tumor involving or influencing lateral pterygoid as well as compression of the maxillary artery lying between two heads of the muscle will have negative influence on nasal blood supply. In our study, it was determined in $57.1 \%$ of the cases (8/14) that maxillary artery lies between two heads of the lateral pterygoid.

Anesthesia of mandibular nerve and its branches is very commonly used in dentistry. It is mentioned that intraarterial injection to maxillary artery should be avoided during the application (Pretterklieber et al.). In our study, it was found in all cases that maxillary artery externally crosses branches of mandibular nerve, namely lingual and inferior alveolar nerves. This finding of neighboring relation is concordant with findings of previous studies (Pretterklieber et al.; Isolan et al.). In our cases, it was reported that distance between inferior alveolar nerve and middle meningeal artery was $3.25 \pm 1.65$ (1.69-6.91). Due to this close proximity, it should be considered that both middle meningeal artery and particularly superficial maxillary artery will be under higher influence during the anesthesia of mandibular nerve and its branches.

Inferior alveolar artery supplies the mandible (teeth, alveoli, cortical bone of body of mandible) with many branches. In general, it branches from mandibular part of the maxillary artery (Standring et al.). It is reported that it may rarely branch from external carotid artery (Jergenson et al., 2005). In our study, it was observed that inferior alveolar artery branched from origin section of the maxillary artery by $14.3 \%(2 / 14)$, before the middle meningeal artery by $35.7 \%(5 / 14)$, branched from same localization with middle meningeal artery by $14.3 \%(2 / 14)$ and after the middle meningeal artery by $35.7 \%(5 / 14)$. In surgical interventions to be performed in the region, knowledge on branching variations of the inferior alveolar artery will be useful for preventing negative influence on mandible supply.

It is reported that middle meningeal artery is rarely absent, but it passes from foramen spinosum in 99\% of cases if it is present and it may enter into the skull from foramen ovale if foramen spinosum is absent (Bergman et al.). Middle meningeal artery is detected in all our cases (14/14). Moreover, it is reported that middle meningeal artery branches usually as the first branch in superficial maxillary artery cases, but it may vary in deep cases. While it was found that middle meningeal artery was given as first branch in five of superficial maxillary arteries and it was branched in conjunction with the inferior alveolar artery. It was determined that it was given in conjunction with inferior alveolar artery in one of deep cases and it was given after inferior alveolar artery in five cases.

It is mentioned that accessory meningeal artery is present in $96 \%$ of subjects and it is given from middle 
meningeal artery in maxillary artery cases with superficial course and it is given from maxillary artery in maxillary artery cases with deep course (Bergman et al.). It is reported that double accessory middle meningeal artery may be found (Bergman et al.). In our study, 8 accessory meningeal arteries were found. It was observed that middle meningeal artery is given from common trunk in 3 of cases with superficial course. Therefore, we believe that branching point and way of the accessory meningeal artery is not related with superficial/deep course of maxillary artery. One accessory meningeal artery lied among fibers of inferior alveolar nerve. This condition suggests the possibility of arterial damage during anesthesia of the nerve.

Making important contributions for supplying nasal septum, sinuses and nasal conches, sphenopalatine artery is the last branch of the maxillary artery and it enters into nasal cavity from sphenopalatine foramen. If nasal pack for controlling severe epistaxis leads to pain and extreme discomfort and if nasal obstruction, dysphagia and occlusion of auditory tube are present and no response can be obtained from medication and pack therapy, arterial ligation is applied (Abelson et al.; Maceri). Transanthral, transoral or endonasal endoscopic intervention methods are used for ligating the 3rd part of the maxillary artery and sphenopalatine artery (Stepnick et al., 1990; Abelson et al.; Maceri; Voegels et al., 2001; Schwartzbauer et al.; Kumar et al., 2003; Pradess et al., 2008; Abuzayed et al.). Arterial embolization is used as an alternative and efficient method for persistent posterior epistaxis cases and it is performed under angiographic guidance (Maceri). Last part of the maxillary artery, attempted to be reached in all applications, is typed according to the branching means of the sphenopalatine artery and descending palatine artery. Results of previous studies and of our study are shown in Table III that higher rate of type "Y" in our cases $(50 \%)$ is remarkable.

There are studies investigating the availability of maxillary artery directly as arterial donor in the repair of internal carotid artery dissections and aneurysms due to close proximity of the artery with cranial base (Vrionis et al.; Buyukmumcu et al.). Aneurysms of maxillary artery are extremely rare and it is usually diagnosed when rupture of the aneurysm occurs (Lang). There are technical studies indicating that maxillary artery can be easily accessed using the infratemporal crest as reference point and bypass to the supraclinoid section of the internal carotid artery or proximal of the middle cerebral artery can be made using vein/artery graft via this route (Karabulut et al., 2001; Ustun et al., 2004). We believe that diameter and length data presented in Tables I and II will provide useful information to relevant researchers on availability of maxillary artery as donor, arterial embolization in the persistent posterior epistaxis or in radiological imaging which shows aneurysms by chance.

In conclusion, in our study, a general overview assessment including significant data and reminders for head and neck surgeons, dentists, neurosurgeons and radiologists in relations with anatomy and maxillary artery and its branches and thus, clinical significance is emphasized.

Table III. Classification comparisons based on branching means of last part of the maxillary artery (Morton \& Khan, 1991).

\begin{tabular}{lcccc}
\hline & Y type $\%$ & Inter type \% & T type \% & M type \% \\
\hline Morton \& Kahn (1991) & 33 & 50 & 0 & 16.5 \\
Choi \& Park (2003) & 19 & 33.3 & 23.8 & 14.3 \\
Abuzayed et al. (2009) & 16.7 & 33.3 & 16.7 & 33.3 \\
Kwakk et al. (2010) & 19 & 36 & 28 & 17 \\
Our study & 50 & 14.3 & & 35.7 \\
\hline
\end{tabular}

UYSAL, I. I,; BUYUKMUMCU, M.; DOGAN, N. U.; SEKER, M. \& ZIYLAN, T. Significado clínico de la arteria maxilar y sus ramas: Un estudio en cadáver y la revisión de la literatura. Int. J. Morphol., 29(4):1274-1281, 2011.

RESUMEN: El objetivo de este estudio fue investigar la anatomía de la arteria maxilar (AM) y sus ramas. Fueron disecados 14 hemicabezas de cadáveres turcos adultos. Las muestras fueron clasificadas de acuerdo a las relaciones entre AM y el músculo pterigoideo lateral. Después de la eliminación del músculo pterigoideo lateral, las partes y las ramas de AM fueron expuestas. Se clasificaron los patrones de ramificación de la AM en la fosa pterigopalatina. El calibre y la longitud de las arterias, la distancia entre el arco cigomático y la AM , y entre la cresta infratemporal y la AM fueron medidas. La AM se encuentra superficial al músculo pterigoideo lateral en el 57,2\%. La arteria alveolar inferior (AI) se originó desde la AM antes que la arteria meníngea media (MM) en el 35,7\%, y después de ésta en el 35,7\%. La AI y MM se originaron en la misma zona de la AM en el 14,3\%. En otros dos casos la AI se originó desde el inicio de AM (14,3\%). De acuerdo con los contornos de la tercera porción de AM, se clasificaron como tipo "Y" (50\%), tipo "intermedio-T" (14,3\%), y de tipo "M" (35,7\%). Esta investigación de la anatomía clínica de la AM puede proporcionar información útil a los cirujanos de cabeza y cuello, odontólogos, neurocirujanos y radiólogos relacionados con esta región.

PALABRAS CLAVE: Arteria maxilar; Arteria alveolar inferior; Arteria meníngea media; Cadáver humano. 


\section{REFERENCES}

Abelson, T. I. Epistaxis. In: Paparella, M. M.; Shumrick, D. A.; Gluckman, J. L. \& Meyerhoff, W. L (Eds). Otolaryngology: Head and Neck. Philadelphia: Saunders Company, 1991. pp. 1831-9.

Abuzayed, B.; Tanriover, N.; Gazioglu, N.; Cetin, G. \& Akar, Z. Extended endoscopic endonasal approach to the pterygopalatine fossa: anatomic study. J. Neurosurg. Sci., 53(2):37-44, 2009.

Bergman, R. A.; Afifi A. K. \& Myauchi, R. 2006. Avalaible in: http:// www.anatomyatlases.org/AnatomicVariants/Cardiovascular/Text/ Arteries/Maxillary.

Buyukmumcu, M.; Ustun, M. E.; Seker, M.; Karabulut, A. K. \& Uysal I. I. Maxillary-to-petrous internal carotid artery bypass: an anatomical feasibility study. Surg. Radiol. Anat., 25 (5-6):368-71, 2003.

Chiu, T. A study of the maxillary and sphenopalatine arteries in the pterygopalatine fossa and at the sphenopalatine foramen. Rhinology, 47(3):264-70, 2009.

Choi, J. \& Park, H. S. The clinical anatomy of the maxillary artery in the pterygopalatine fossa. J. Oral Maxillofac. Surg., 61(1):72-8, 2003.

Hussain, A.; Binahmed, A.; Karim, A. \& Sándor, G. K. Relationship of the maxillary artery and lateral pterygoid muscle in a caucasian sample. Oral Surg. Oral Med. Oral Pathol. Oral Radiol. Endod., 105(1):32-6, 2008

Isolan, G. R; Rowe, R. \& Al-Mefty, O. Microanatomy and surgical approaches to the infratemporal fossa: an anaglyphic three-dimensional stereoscopic printing study. Skull Base, 17(5):285-302, 2007.

Jergenson, M. A; Norton, N. S; Opack, J. M. \& Barritt, L. C. Unique origin of the inferior alveolar artery. Clin. Anat., 18(8):597-601, 2005 .

Karabulut, A. K.; Ustun, M. E.; Uysal, I. I. \& Salbacak, A. Saphenous vein graft for bypass of the maxillary to supraclinoid internal carotid artery: an anatomical short study. Ann. Vasc. Surg., 15(5):548-52, 2001.

Kumar, S.; Shetty, A.; Rockey, J. \& Nilssen, E. Contemporary surgical treatment of epistaxis. What is the evidence for sphenopalatine artery ligation? Clin. Otolaryngol., 28(4):360-3, 2003.

Kwak, H. H.; Jo, J. B.; Hu, K. S.; Oh, C. S.; Koh, K. S.; Chung, I. H. \& Kim, H. J. Topography of the third portion of the maxillary artery via the transantral approach in asians. J. Craniofac. Surg., 21(4):1284-9, 2010.

Lang, J. Skull Base and Related Structures. Atlas of Clinical Anatomy. Stuttgart, Schattauer, 1995. pp.306-7.

Maceri, D. R. Epistaxis and Nasal Trauma. In: Cummings, C. W. (Ed). Otolaryngology-Head and Neck Surgery. Philadelphia, Elsevier Mosby, 1993. pp.727-34.
Morton, A. L. \& Khan, A. Internal maxillary artery variability in the pterygopalatine fossa. Otolaryngol. Head Neck Surg., 104(2):2049, 1991.

Navarro, J. A.; Filho, J. L. \& Zorzetto, N. L. Anatomy of the maxillary artery into the pterygomaxillopalatine fossa. Anat. Anz., 152(5):41333, 1982.

Prades, J. M.; Asanau, A.; Timoshenko, A. P.; Faye, M. B. \& Martin, $\mathrm{Ch}$. Surgical anatomy of the sphenopalatine foramen and its arterial content. Surg. Radiol. Anat., 30(7):583-7, 2008.

Pretterklieber, M. L.; Skopakoff, C. \& Mayr, R. The human maxillary artery reinvestigated: I. Topographical relations in the infratemporal fossa. Acta Anat. (Basel), 142(4):281-7, 1991.

Putz, R. \& Pabst, R. Sobotta: Atlas of human anatomy. Munich, Urban \& Schwarzenberg, 2001. pp.86-7. Volume I.

Sashi, R.; Tomura, N.; Hashimoto, M.; Kobayashi, M. \& Watarai, J. Angiographic anatomy of the first and second segments of the maxillary artery. Radiat. Med., 14(3):133-8, 1996.

Schwartzbauer, H. R.; Shete, M. \& Tami, T. A. Endoscopic anatomy of the sphenopalatine and posterior nasal arteries: implications for the endoscopic management of epistaxis. Am. J. Rhinol., 17(1):63-6, 2003.

Standring, S.; Berkovitz, B. K. B.; Hackney, C. M.; Ruskell, G. L.; Collins, P. \& Wigley, C. In: Standring, S. (Ed.). Head and Neck, Gray's Anatomy: The Anatomical Basis of Clinical Practice. 39 ${ }^{\text {th }}$ ed. Barcelona, Elsevier Churchill Livingstone, 2005. pp. 521-3.

Stepnick, D. W.; Maniglia, A. J.; Bold, E. L. \& Maniglia, J. V. Intraoralextramaxillary sinus approach for ligation of the maxillary artery: an anatomic study with clinical correlates. Laryngoscope, 100(11):1166-70, 1990.

Ustun, M. E.; Buyukmumcu, M.; Ulku, C. H.; Cicekcibasi, A. E. \& Arbag, H. Radial artery graft for bypass of the maxillary to proximal middle cerebral artery: An anatomic and technical study. Neurosurgery, 54(3):667-70, 2004

Voegels, R. L.; Thome, D. C.; Iturralde, P. P. \& Butugan, O. Endoscopic ligature of the sphenopalatine artery for severe posterior epistaxis. Otolaryngol. Head Neck Surg., 124(4):464-7, 2001.

Vrionis, F. D.; Cano, W. G. \& Heilman, C. B. Microsurgical anatomy of the infratemporal fossa as viewed laterally and superiorly. Neurosurgery, 39(4):777-85, 1996

\section{Correspondence to:}

Assist. Prof. Dr. Nadire Unver Dogan

Department of Anatomy

Selcuklu Medical Faculty

Selcuk University

Konya

Received: 06-03-2011

TURKEY

Accepted: 16-08-2011

Email: nunver2003@yahoo.com 